HIAS-E-67

\title{
Trade Liberalization, Absorptive Capacity and the Protection of Intellectual Property Rights
}

\author{
Arghya Ghosh \\ School of Economics, University of New South Wales, Sydney 2052, Australia \\ Jota Ishikawa \\ Faculty of Economics, Hitotsubashi University, Kunitachi, Tokyo 186-8601, Japan
}

April 2018

Hitotsubashi Institute for Advanced Study, Hitotsubashi University

2-1, Naka, Kunitachi, Tokyo 186-8601, Japan

tel:+81 425808604 http://hias.ad.hit-u.ac.jp/

HIAS discussion papers can be downloaded without charge from:

http://hdl.handle.net/10086/27202

https://ideas.repec.org/s/hit/hiasdp.html

All rights reserved. 


\title{
TRADE LIBERALIZATION, ABSORPTIVE CAPACITY AND THE PROTECTION OF INTELLECTUAL PROPERTY RIGHTS
}

\author{
ARGHYA GHOSH AND JOTA ISHIKAWA
}

\begin{abstract}
We examine how trade liberalization affects South's incentive to protect intellectual property rights (IPR) in a North-South duopoly model where a low-cost North firm competes with a high-cost South firm in the South market. The North firm serves the South market through either exports or foreign direct investment (FDI). The extent of effective cost difference between North and South depends on South's imitation, which in turn depends on South's IPR protection and absorptive capacity and North firm's location choice, all of which are endogenously determined in our model. For a given level of IPR protection, South's absorptive capacity under exports may be greater than under FDI. Even though innovation is exogenous to the model (and hence unaffected by South's IPR policy), strengthening IPR protection in South can improve its welfare. The relationship between trade costs and the degree of IPR protection that maximizes South welfare is non-monotone. In particular, South has an incentive to protect IPR only when trade costs are moderate. When masking technology or licensing is incorporated into the model, however, some protection of IPR may be optimal for South even if the trade costs are not moderate.
\end{abstract}

JEL classification numbers: F12, F13, D43

Keywords: intellectual property rights (IPR), absorptive capacity, imitation, foreign direct investment (FDI), licensing, masking, oligopoly, North-South trade model

Date: January 2018.

We are grateful to Bob Staiger, Wolfgang Keller, Steve Yeaple, seminar participants at various universities and conferences including Asia Pacific Trade Seminars (APTS), Australasian Trade Workshop, European Trade Study Group (ETSG) Meetings, Midwest Trade Meetings, Hitotsubash Conference on International Trade and FDI, the Japanese Association for Applied Economics, and the Conference of the European Association for Research in Industrial Economics for valuable comments. Ghosh is grateful for financial support from the Australian Research Council. Ishikawa acknowledges financial support from the Japan Society for the Promotion of Science through the Grant-in-Aid for Scientific Research (S), Grant Number 26220503.

Ghosh: School of Economics,University of New South Wales, Sydney 2052, Australia, E-mail: a.ghosh@unsw.edu.au; Ishikawa: Faculty of Economics, Hitotsubashi University, Kunitachi, Tokyo 186-8601, Japan, and RIETI, Chiyoda, Tokyo, Japan, E-mail:jota@econ.hit-u.ac.jp. 


\section{INTRODUCTION}

Globalization leads to technology transfers/spillovers from developed countries (North) to developing countries (South). A typical channel of technology transfers/spillovers is trade and foreign direct investment (FDI), which make it easier for South firms to imitate superior production technologies in North. However, such imitation is neither automatic nor costless (Grossman and Helpman, 1991; Helpman, 1993; Branstetter and Saggi, 2011). The extent of imitation depends crucially on South's absorptive capacity, i.e., South's ability to effectively copy the superior technologies of North.

South's imitation activities are also importantly affected by South government's policies and North firms' strategic decisions (e.g. location). In particular, imitation is strongly influenced by the strength of intellectual property rights (IPR) protection in South. If IPR protection is perfect and fully enforced, patented technologies cannot freely be copied. When IPR protection is imperfect, North firms may mask their technologies to deter South firms from copying them unless masking is too costly. Furthermore, North firm's location choice affects South's imitation, because geographical proximity plays an important role in technology spillovers (see, for example, Eaton and Kortum, 1999; Branstetter, 2001; Keller, 2002, and Bilir, 2012). When North firms serve the South market, South's imitation is easier under FDI than under exports.

In this paper, we examine South's incentive to protect IPR in a North-South duopoly model where a low-cost North firm competes with a high-cost South firm in the South market. The extent of effective cost difference between North and South specifically depends on South's imitation. As discussed above, imitation depends on North firm's location choice, its masking decision, South's absorptive capacity (or, absorptive ability) and most importantly South's IPR protection, all of which are endogenously determined in our framework.

Strengthening IPR protection boosts innovation. While that argument is well understood, critics of stronger IPR regimes in South argue that there is little appreciable effect of IPR protection in South on North innovation (Branstetter and Saggi, 2011). Furthermore, as argued by Maskus (2000) and Maskus and McDaniel (1999), imposing a strong IPR regime might retard industrial development of the developing countries. Taking these arguments seriously, we assume that North innovation, which is presumably the source of North's cost advantage, is exogenously given. Instead, we incorporate North firm's other decisions (e.g., location choice and masking behavior) into our model and show that incorporating these features and endogenizing South firm's imitation efforts to establish absorptive capacity have important IPR policy implications for South. In particular, we show that South can benefit from strengthening its own IPR protection even when North innovation is unaffected by its IPR policy.

To make our analysis tractable, we assume that the trade liberalization is caused by a decrease in trade costs, which is beyond the control of the South government. 
That is, trade costs are declining as the result of a decrease in transport costs and a pre-commitment to the reduction of trade barriers. Hence, the policy instrument the South government can freely set is only the degree of IPR protection. We find that the relationship between trade costs and South's incentive to protect IPR can be subtle. In particular, we show that trade liberalization can mute or amplify the North-South conflict regarding IPR protection, depending on the trade costs.

To understand our implications better, we present more details of our North-South duopoly model. A North firm (firm $N$ ), in our framework, has zero cost of production while a South firm (firm $S$ ) starts with unit cost $c(>0)$. Given trade costs, the South government chooses the level of IPR protection $\alpha \in[0,1]$ where $\alpha=0$ implies full protection of IPR while $\alpha=1$ implies no protection of IPR. The strength of IPR protection declines as $\alpha$ increases. Following South government's choice of $\alpha$, firm $N$ decides whether to export to South market or serve it via FDI. If firm $N$ opts to export to South market, it incurs a trade cost of $t$ per unit. After the firm $N$ 's decision has been made, firm $S$ chooses the level of imitation efforts, i.e., the level of investment $C(z)$ in absorptive capacity which reduces its unit cost from $c$ to $c(1-\alpha z)$ (where $z \in[0,1])$. As imitation is easier with FDI, we assume that $C(z)$ is lower under FDI.

Given that Cournot analysis is standard, let us start with the exports versus FDI decision. If firm $N$ chooses FDI, it avoids per unit trade cost. However, FDI makes the absorption of new technology easier for firm $S$, which can partially erode North's cost advantage. When IPR protection is weak, the erosion of North's cost advantage is higher. This trade-off between trade cost savings and reduction in cost-advantage is key to the location choice decision by firm $N .^{1}$

The second and probably more important component of our analysis is the endogenous determination of South's absorptive capacity. If South's absorptive capacity is low, then South's IPR protection policy has little effect. While part of a firm's absorptive capacity can be viewed as its innate ability to absorb new technology - and hence can be treated as exogenous - presumably, the capacity could be changed via investment, i.e., imitation efforts.

By locating in South, FDI makes imitation easier for firm $S$, which encourages investment in absorptive capacity. However, as firm $N$ saves per unit trade cost, its effective unit cost of production declines with FDI. This reduces firm $S$ 's output and consequently its incentive to invest in absorptive capacity. We find that absorptive capacity and consequently productivity spillovers - effective cost reduction in our frameworkcould be higher or lower with FDI. Such ambiguity only arises when absorptive capacity is endogenously determined.

\footnotetext{
${ }^{1}$ In addition to trade cost savings, North firm can also enjoy other forms of cost advantage, e.g., low input cost in South, which might make FDI even more attractive for North. Incorporating other forms of cost advantage will not alter our analysis as long as the magnitudes of these cost-advantages are exogenously given.
} 
The ambiguity might seem surprising as it is often thought that FDI benefits South through technology and knowledge spillovers to the local rivals (Keller, 2004). See, for example, Dimelis and Louri (2002), Griffith, Redding and van Reenen (2003), Javorcik (2004), Chakraborty and Nunnekamp (2008) and Suyanto, Salim and Bloch (2009) for evidence on positive productivity spillovers. On the other hand, Aitken and Harrison (1999), Djankov and Hoekman (2000), and Barry, Gorg and Strobl (2005) found a negative relationship between FDI and spillovers. By endogenizing investment in absorptive capacity, our theoretical analysis offers an explanation for the ambiguous relationship.

Finally, we turn to IPR protection. Recall that firm $N$ 's unit cost is exogenously given and not affected by South's IPR policy. As South strengthens its IPR protection, South's marginal cost increases which in turn reduces profits and consumer surplus for South. Thus, strengthening IPR protection might seem to reduce South's welfare. Indeed, if location choice or masking behavior is not an issue, this argument holds. For example, if trade costs are prohibitive with location choice, firm $N$ has no choice but to opt for FDI. In this case, it is optimal for South to offer no protection for IPR. However, if trade costs are not prohibitive, firm N's losses under FDI from high spillovers (induced by weak IPR) might outweigh the gains from saving trade costs. Thus, weak IPR might lead firm $N$ to opt for exports. If firm $N$ chooses exports, it might be bad for South as well. As firm $N$ incurs trade costs under exports, the equilibrium price is higher, which hurts consumers. This negative effect is reinforced if investment in absorptive capacity is lower under exports. We find that indeed, for a range of parameterizations, it is in South's interest to strengthen IPR protection just enough that firm $N$ opts for FDI.

Interestingly, we find a non-monotone relationship between trade costs and the level of IPR protection that maximizes South's welfare in the presence of location choice. If the trade cost is too high, IPR protection (to induce FDI) is not necessary, since in that case the North firm opts for FDI anyway. If the trade cost is too low, strengthening IPR protection does not improve welfare, either. Strengthening IPR protection improves South's welfare only for moderate values of trade costs.

In section 3 , we show that strengthening IPR protection can induce firm $N$ to choose FDI over exports, which in turn improves South's welfare. However, this is not the only channel through which IPR can improve welfare. In section 4, we abstract away from location choice decision (by assuming that there are no trade costs) and focus on masking decision because North firms often undertake a variety of costly activities to prevent the imitation of its technology (see section 4 for details). To capture costly masking, we consider a model where firm $N$ 's effective unit cost is $m$ if it masks its technology and zero otherwise. Masking increases the cost of investment in absorptive capacity for firm $S$. 
In terms of effects, we find that masking is similar to exports, while non-masking is similar to FDI. Firm $N$ engages in masking if and only if IPR protection in South is not sufficiently strong. In this setup we show that strengthening IPR protection can improve South's welfare by deterring firm $N$ from masking its technology. As in the case of trade costs, we find that protection is optimal only for intermediate values of $m$. Irrespective of the strength of IPR protection, firm $N$ masks its technology when $m$ is low and does not mask when $m$ is high. In the intermediate range of values of $m$ however, strengthening IPR protection deters masking and improves South's welfare.

In our model, FDI facilitates imitation which in turn reduces the production cost of firm $S$. However, anticipating imitation, firm $N$ might license and transfer its technology to firm $S$. Incorporating licensing in our model, and assuming away location choice, we find that strengthening IPR protection can improve South's welfare in a range of parameterizations. In particular, we find that IPR protection can improve South welfare when the difference in the unit costs between firm $N$ and firm $S$ is not too high or not too low. If the cost difference is too low, firm $N$ will always license its technology to firm $S$. If the cost difference is too high, firm $N$ will never license its technology irrespective of the the strength of IPR protection. For moderate differences in costs, IPR protection plays an important role. Strengthening IPR protection improves South welfare, because it induces firm $N$ to license its technology to firm $S$. This result is consistent with empirical findings (for example, see Branstetter, Fisman and Foley, 2006; and Kanwar, 2012).

The plan of the paper is as follows. Section 2 describes the relationship between our analysis and previous IPR literature. Section 3 explores the four-stage game with North firm's location choice. We find the optimal IPR policy from South's perspective, taking into account the impact of the degree of IPR protection on absorptive capacity and location choice. Section 4 investigates a three-stage game with North firm's masking behavior instead of location choice. Section 5 compares licensing with FDI. Section 6 offers concluding remarks.

\section{Relation to Previous Literature}

In this section, we briefly relate the present study to previous North-South trade literature from the viewpoint of IPR protection. ${ }^{2}$ Helpman (1993) provided the first general equilibrium analysis of IPR policy in a North-South product cycle model with innovation, imitation and growth. The early works in this area (Helpman,1993; Glass and Saggi, 2002) find that strengthening IPR protection in South reduces South welfare and may or may not benefit North. Lai (1998) argues that if FDI is the channel of

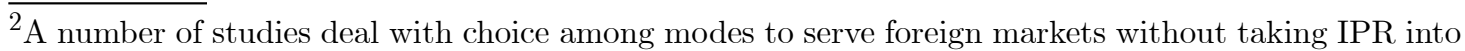
account. Examples include Horstmann and Markusen (1987), Ethier and Markusen (1996) and Saggi (1996). Saggi (2002) surveys the literature.
} 
technology transfer from North to South implying imitation occurs only under FDI, the conclusion no longer holds.

Branstetter and Saggi (2011) push this literature based on North-South product cycle models further by making both imitation and FDI endogenous. Branstetter, Fisman, Foley and Saggi (2011) show that while the imitation activities decline in South with the strengthening of its IPR regime, the expansion of multinational activity can more than offset the decline. Examining the responses of U.S.-based multinationals and domestic production to a set of IPR reforms in the 1980s and 1990s, they confirm that is indeed the case. Most papers in this literature evaluate the welfare consequence of marginal changes in imitation to analyze the impact of IPR protection. An exception is the paper by Grossman and Lai (2004). They explicitly consider both (i) simultaneous choice of IPR protection by trade partners and (ii) a globally efficient regime of IPR protection in a multi-country, trading world where countries differ in their size and innovation capacities.

Despite offering valuable and rich insights, these dynamic North-South general equilibrium models often do not involve strategic interaction among firms, which is often a key component of analysis in the oligopolistic markets (Yang and Maskus, 2009). For detailed microeconomic analysis of firm and government behavior, we adopt a partial equilibrium, Cournot duopoly framework. This allows us to capture crucial firm level decisions such as where to locate or how much to invest, in a detailed fashion.

In a simple North-South duopoly model with Cournot competition, Chin and Grossman (1990) showed that no protection of IPR is better than the full protection of IPR for South's welfare. Examining the welfare effects of the geographical scope of patent coverage, Deardorff (1992) reports similar results. Both Chin and Grossman (1990) and Deardorff (1992) consider binary choice regarding protection of IPR: full protection or no protection. Allowing for various degrees of IPR protection as well as for differences in preference and technology, Diwan and Rodrik (1991) show that South might benefit from protection of IPR if the differences in preferences are substantial. Introducing R\&D with spillovers into a North-South duopoly model, Žigić $(1998,2000)$ shows that the result obtained in Chin and Grossman (1990) is no longer robust. He specifically regards the intensity of spillover as an indicator of the strength of the IPR protection. He assumes that if North firm's cost-reducing R\&D decreases its own marginal cost (MC) by 1 , then it also lowers South's MC by $\alpha \in[0,1]$, which is an indicator of the strength of the IPR protection.

Recent empirical evidence shows that the presence of foreign firms does not automatically lead to technology spillovers, however. Rather, it depends importantly on local firms' investment in R\&D related activities (Kathuria, 2000; Griffith, Redding and van Reenen, 2003; Suyanto, Salim and Bloch, 2009). Naghavi (2007) extends Žigić (1998) by considering the possibility of FDI and decomposing the intensity of spillovers into the strength of the IPR protection and the extent of absorptive capacity just like 
$\alpha z$ in our model. Naghavi (2007) shows that South can always gain from enforcing stringent IPR protection, either by attracting FDI in less R\&D-intensive sectors or by stimulating innovation in high-technology sectors. Yang and Maskus (2009) also have absorptive capacity in their work. They focus on a scenario in which the North firm chooses either exports or technology transfer through licensing. They show that by encouraging technology transfer, South's stronger IPR protection might improve the ability of South firms to break into export markets and that South's welfare depends on its absorptive capacity.

The key difference between our work and existing works in partial equilibrium based IPR literature in general, and Žigić(1998), Naghavi (2007) and Yang and Maskus (2009) in particular, is that we treat absorptive capacity as endogenous by explicitly modelling South firm's imitation efforts to obtain absorptive capacity. The endogeneity is important in our framework for two reasons. If the absorptive capacity is exogenous and the same under FDI and exports in our model, both the location choice decision for North and the optimal IPR policy become trivial: North always chooses FDI and South offers no protection of IPR. ${ }^{3}$ Alternatively, appealing to common wisdom, one can assume that absorptive capacity is higher under FDI than exports. However, that would not be innocuous as we have discussed earlier (and formally demonstrate in Proposition 2), that the absorptive capacity under FDI could be higher or lower than that under exports.

Grünfeld (2006) also explicitly models the concept of absorptive capacity in an international duopoly model. In his framework, both domestic and foreign firms engage in cost-reducing $R \& D$, which also determines the $R \& D$ spillover rate. Except for the endogenous determination of absorptive capacity, however, there is little similarity between his work and ours. We are concerned with South's incentive to protect IPR in the process of trade liberalization, which is absent in Grünfeld (2006). Moreover, since he assumes two-way spillovers, his model is better suited to analyzing spillovers between developed countries. In contrast, we deal with one-way spillovers from North to South, which seems more appropriate for analyzing South's imitation of North. Also, the masking behavior of North firms is not explicitly considered in Grünfeld (2006).

Taylor (1993) explicitly incorporates North's masking efforts and South's reverse engineering efforts in a North-South duopoly model to examine the relationship between the IPR protection in South and technology transfers. Our model is related to Taylor's work as we also endogenize South's imitation efforts, and North's masking decision. However, in contrast to Taylor(1993), where masking is modelled as an increase in fixed costs for the North firm, we assume that masking increases the variable cost for

\footnotetext{
$\overline{{ }^{3} \text { In a different }}$ context, Ishikawa and Horiuchi (2012) investigate firm's strategic location choice in the presence of technology spillovers with exogenous absorptive capacity. However, IPR is absent from their analysis.
} 
the North firm. ${ }^{4}$ An important implication of our specification is that as the North firm switches from non-masking to masking, the South firm can increase its imitation efforts. Also, as masking is a binary decision in our framework - see section 4 for detailsstrengthening of IPR protection in South can deter North firms from masking but it does not necessarily do so. Strengthening IPR protection deters masking and improves South's welfare only if the cost of masking is not too high or too low. Note that masking per se is not the main focus of our paper. In fact, as we show in section 3, a case for strengthening IPR protection in South exists when location (rather than masking) is the key decision variable for the North firm. In section 4 , we simply show that such a model with endogenous location choice could be translated to a model with endogenous masking decision without much substantive change.

Earlier papers in the literature on trade and licensing assume that licensing is costless, that is, licensing does not involve resource costs. Examples include Kabiraj and Marjit (1993, 2003), Mukherjee and Pennings (2006), Ishikawa (2007), and Horiuchi and Ishikawa (2009). These studies are primarily concerned with how government can induce technology transfers through subsidies or tariffs in the presence of strategic use of licensing. The interaction between IPR protection and licensing is not examined. The role of IPR in the context of trade and licensing is discussed in Yang and Maskus (2009). Introducing costly licensing in an oligopoly framework, they convincingly argue that strengthening IPR protection can benefit South by reducing the costs of technology transfer. In contrast, in our analysis, licensing induced by stronger IPR protection benefits consumers and hence South gains.

\section{Model with Location Choice}

3.1. Setup. There are two countries, North and South, each with one firm denoted by firm $N$ and firm $S$ respectively. These firms sell a homogenous product in the South. As we are primarily interested in the incentives and welfare consequences of strengthening IPR protection in South, we assume that all consumers are located in South. The inverse demand for the product in the South is

$$
\begin{aligned}
P & =b-Q \\
& =b-\left(q_{N}+q_{S}\right),
\end{aligned}
$$

where $q_{i}(i=N, S), Q \equiv q_{N}+q_{S}$ and $P$ respectively denote output of firm $i$, aggregate output and market price.

\footnotetext{
${ }^{4}$ Whether masking is better modeled as an increase in fixed cost (as in Taylor, 1993) or an increase in marginal cost (like ours) depends on the context. Consider for example the list of masking activities mentioned in Taylor (1993): software programming traps, copy-protect schemes, the encryption of important codes, maintaining a vigilant legal department, and monitoring the imports of similar foreign products. While the last two activities can be captured via an increase in fixed costs, the others may fit well with an increase in marginal cost.
} 
Firm N's marginal cost of production is assumed to be zero. Firm $N$ can either locate in North and export to South, incurring a trade cost of $t>0$ per unit of $q_{N}$. Otherwise, it can opt for FDI in South. That is, firm $N$ can build a plant in South and serve the South market from that plant. In that case, firm $N$ does not incur the trade costs. For simplicity, we assume that there are no fixed costs for setting up a plant in South. ${ }^{5}$

Firm $S$ is located in South. The initial unit cost of production for firm $S$ is a constant $c>0$. However, the effective unit cost for firm $S$ is

$$
c_{S}=c(1-\alpha z) ; \quad \alpha \in[0,1], \quad z \in[0,1],
$$

where $z$ denotes the absorptive capacity (or, the imitation ability) of firm $S$ and $\alpha$ captures the degree of IPR protection in South. If $\alpha=0$, intellectual property rights are fully protected while if $\alpha=1$, there is no protection of IPR. As $\alpha$ increases from zero to unity the protection becomes weaker. Weakening of the IPR protection in South reduces the cost advantage of firm $N$. However, even with no IPR protection (i.e., $\alpha=1$ ) firm $N$ enjoys some cost advantage as long as $z<1$.

Firm $S$ has to make an effort to develop absorptive capacity. To attain the capacity level $z$, firm $S$ has to incur costs, $C(z)$. In the following, we refer to this effort as investment in absorptive capacity. We assume that $C(0)=0, C^{\prime}(z)>0$ and $C^{\prime \prime}(z)>0$ for all $z>0$. Furthermore, to obtain closed-form solutions, we consider $C(z)=k z^{2}$, where $k=k^{E}$ if firm $N$ opts for exports and $k=k^{F}$ if firm $N$ opts for FDI.

We assume that $k^{E}>k^{F}$. Several authors including Eaton and Kortum (1999), Branstetter (2001), and Keller (2002) among others have pointed out that proximity facilitates imitation. In other words, absorption is easier when firms are geographically closer to each other. This might be due to the possibility of worker mobility between firms $N$ and $S$ or other mechanisms (e.g., both firms buying local inputs from a common supplier). ${ }^{6}$

The timing of the events is as follows.

Stage 1 [Exports or FDI]: Given $\alpha$ - which we assume to be exogenous until subsection 3.5 - firm $N$ decides whether to serve the South market via exports or FDI. Let $e$ denote the binary variable capturing the firm $N$ 's mode of serving the South market where

$$
e=\left\{\begin{array}{l}
1, \text { if firm } N \text { exports to South; } \\
0, \text { if firm } N \text { serves South by FDI. }
\end{array}\right.
$$

\footnotetext{
${ }^{5}$ To be precise, the cost of building a first plant in South is zero, while the cost of building a second plant is prohibitive. Thus, effectively, the number of North plants in South is either zero or one.

${ }^{6}$ For some products, it is possible that $k^{E}=k^{F}$, e.g., if reverse-engineering is equally effective irrespective of the location of the North firm. We ignore this special case since then the North firm would always choose FDI in our framework.
} 
Stage 2 [Investment in absorptive capacity]: Given $\alpha$ and $e$, firm $S$ chooses the level of absorptive capacity $z$.

Stage 3 [Cournot competition]: Given $\alpha, e$, and $z$, each firm $i$ chooses $q_{i}$ to maximize its profits taking the rival firm's output, $q_{j}$, as given $(i, j \in\{N, S\}, i \neq j)$.

A few remarks are in order regarding the assumptions of the model. First, the assumption that firm $N$ 's marginal cost is zero is innocuous. Second, the fact that there are no fixed costs for FDI simplifies the algebra but is not crucial for our results. Introducing a strictly positive plant-specific fixed cost would make FDI less preferable to exports. Third, we have implicitly assumed that the North and South markets are segmented and that firm $S$ does not sell in North. Introducing the possibility that firm $S$ exports to North does not qualitatively change our findings unless the North government sets policy strategically. Finally, our cost specifications, i.e. $c_{S}=c(1-\alpha z)$ and $C(z)=k z^{2}$, suggest that unless firm $S$ invests in absorptive capacity, the cost difference between firms $N$ and $S$ stays at $c$. An alternative specification could be $c_{S}=c\left(z_{0}\right)(1-\alpha z)$ where $0<c\left(z_{0}\right)<c=c(0)$ holds for all $z_{0}>0$. The term $z_{0}$ could be interpreted as the innate imitation ability of firm $S$. We chose to work with $c\left(z_{0}\right)=c$ because this greatly simplifies the algebra.

Now we turn to characterizing the unique Subgame Perfect Nash Equilibrium (SPNE) of the game. To facilitate this characterization, we make a number of simplifying assumptions regarding the upper and lower bounds of different parameters:

Assumption 1: (i) $c<\frac{b}{2}$, (ii) $t<\frac{b}{2}$, and (iii) $k^{F}>\frac{b^{2}}{9}$.

Assumption 1 implies that the initial marginal cost of firm $S$ is such that it produces a strictly positive amount of output for all $(\alpha, e, z)$ satisfying $\alpha \in[0,1], e \in\{0,1\}$ and $z \in[0,1]$. The bound for $t$ in Assumption 1(ii) ensures that firm $N$ sells a strictly positive amount in South even when it chooses to export. Assumption 1(iii) ensures that the second-order condition of the stage 2 optimization problem is satisfied and the equilibrium value of $z$ is strictly interior (i.e. lies between zero and unity).

3.2. Cournot equilibrium. First consider the stage 3 game where the two firms compete in quantities. Prior to this stage, the degree of IPR protection in $\operatorname{South}(\alpha)$, North firm's mode of entry $(e)$ and South firm's absorptive capacity $(z)$ have been chosen. So, both firms $S$ and $N$ take these variables as given.

For a given $(\alpha, e, z)$, firm $S$ chooses $q_{S}$ to maximize $\left(b-q_{N}-q_{S}-c(1-\alpha) z\right) q_{N}$ while firm $N$ chooses $q_{N}$ to maximize $\left(b-q_{N}-q_{S}-e t\right) q_{N}$. Routine computation yields:

$$
\tilde{q}_{N}(\alpha, e, z)=\frac{b-2 e t+c(1-\alpha z)}{3}, \quad \tilde{q}_{S}(\alpha, e, z)=\frac{b-2 c(1-\alpha z)+e t}{3},
$$




$$
\begin{gathered}
\tilde{Q}(\alpha, e, z) \equiv \tilde{q}_{N}(\alpha, e, z)+\tilde{q}_{S}(\alpha, e, z)=\frac{2 b-e t-c(1-\alpha z)}{3}, \\
\tilde{\pi}_{N}(\alpha, e, z)=\frac{(b-2 e t+c(1-\alpha z))^{2}}{9}, \quad \tilde{\pi}_{S}(\alpha, e, z)=\frac{(b-2 c(1-\alpha z)+e t)^{2}}{9},
\end{gathered}
$$

where $\tilde{q}_{i}(\alpha, e, z)$, and $\tilde{\pi}_{i}(\alpha, e, z)$ denote the quantity and profits of firm $i(=N, S)$ in the Cournot equilibrium. The following lemma records comparative statics results for future reference.

Lemma 1. For any given location choice (i.e., $e=0$, or $e=1$ ),

(i) $\tilde{q}_{N}(\alpha, e, z)$ and $\tilde{\pi}_{N}(\alpha, e, z)$ are decreasing in $\alpha$ and $z$.

(ii) $\tilde{q}_{S}(\alpha, e, z)$ and $\tilde{\pi}_{S}(\alpha, e, z)$ are increasing in $\alpha$ and $z$.

(iii) $\tilde{Q}(\alpha, e, z)$ is increasing in $\alpha$ and $z$.

Both the weakening of IPR protection (i.e., an increase in $\alpha$ ) and an increase in absorptive capacity (i.e., an increase in $z$ ) reduces the unit cost of firm $S$. This in turn increases firm $S$ 's output and profits. Firm $N$ 's output and profits decline since $\tilde{q}_{S}(\alpha, e, z)$ and $\tilde{q}_{N}(\alpha, e, z)$ are strategic substitutes. Part (iii) is a standard result from Cournot competition: aggregate output increases as unit cost declines (through an increase in $\alpha$ or $z$ in this case).

3.3. Absorptive Capacity. Consider stage 2 where firm $S$ chooses the level of absorptive capacity $z$. For a given degree of IPR protection, $\alpha$, and firm $N$ 's location choice, $e$, firm $S$ chooses $z$ to maximize

$$
\tilde{\pi}_{S}(\alpha, e, z)-k(e) z^{2} \equiv \pi_{S}(\alpha, e, z)
$$

where $k(e) \equiv e k^{E}+(1-e) k^{F}$. The marginal cost of investment in $z$ is

$$
2 k(e) z
$$

while the marginal benefit from investment in absorptive capacity, given by $\frac{\partial \tilde{\pi}_{S}(\alpha, e, z)}{\partial z}$ is:

$$
\frac{\partial \tilde{\pi}_{S}(\alpha, e, z)}{\partial z}=2 \tilde{q}_{S}(\alpha, e, z) \frac{\partial \tilde{q}_{S}(\alpha, e, z)}{\partial z}=\frac{2 \alpha c(b-2 c(1-\alpha z)+e t)}{9} .
$$

Equating marginal cost with the marginal benefit of investment in $z$ gives South firm's absorptive capacity in stage 2 equilibrium:

$$
z=\frac{2 \alpha c(b-2 c+e t)}{9 k(e)-4 \alpha^{2} c^{2}} \equiv z(\alpha, e)
$$

where $\alpha \in[0,1]$ and $e \in\{0,1\}$. The following proposition follows immediately from the expression of $z(\alpha, e)$.

PROPOSITION 1. Absorptive capacity, given by $z(\alpha, e)$,

(i) increases as the degree of IPR protection weakens; 
(ii) decreases as (a) the cost of investment $(k(e))$ rises, and (b) the trade cost $(t)$ falls.

To understand Proposition 1, recall the effective cost of production for firm $S: c_{S}=$ $c(1-\alpha z)$. As $z$ increases, $c_{S}$ declines, which raises firm $S$ 's profits. The weaker the IPR protection, the larger is the decline in $c_{S}$ and consequently the larger the increase in firm $S$ 's stage 3 profits. This logic, together with the fact that marginal cost of investment, $k(e) z$, is independent of the degree of IPR protection imply Proposition 1(i).

The relationship between the cost of investment, $k(e)$, and absorptive capacity is straightforward. Concerning trade costs, note that $z(\alpha, 0)$ is independent of $t$. Thus trade cost $t$ matters only if firm $N$ exports. As the trade cost falls, firm $N$ 's effective unit cost declines. It produces more, and since quantities are strategic substitutes, firm $S$ produces less. A reduction in $\tilde{q}_{S}(\alpha, 1, z)$ lowers South's marginal benefit from investment in absorptive capacity which in turn reduces $z(\alpha, 1)$.

Let $z^{F}\left(z^{E}\right)$ denote the equilibrium absorptive capacity of firm $S$ when firm $N$ chooses FDI (exports). Using (7) we get:

$$
\begin{gathered}
z^{F} \equiv z(\alpha, 0)=\frac{2 \alpha c(b-2 c)}{9 k^{F}-4 \alpha^{2} c^{2}}, \\
z^{E} \equiv z(\alpha, 1)=\frac{2 \alpha c(b-2 c+t)}{9 k^{E}-4 \alpha^{2} c^{2}} .
\end{gathered}
$$

Define $q_{i}^{F} \equiv \tilde{q}_{i}\left(\alpha, 0, z^{F}\right), \pi_{i}^{F} \equiv \tilde{\pi}_{i}\left(\alpha, 0, z^{F}\right)$ and $Q^{F} \equiv \tilde{Q}\left(\alpha, 0, z^{F}\right)$ where $q_{i}^{F}, \pi_{i}^{F}$ and $Q^{F}$ respectively denote firm $i$ 's quantity, firm $i$ 's profits and aggregate output in stage 2 equilibrium when the North firm opts for FDI in stage 1 . Similarly $q_{i}^{E} \equiv \tilde{q}_{i}\left(\alpha, 1, z^{E}\right)$, $\pi_{i}^{E} \equiv \tilde{\pi}_{i}\left(\alpha, 1, z^{E}\right)$ and $Q^{E} \equiv \tilde{Q}\left(\alpha, 1, z^{E}\right)$ respectively are firm $i$ 's output, firm $i$ 's profits and aggregate output in stage 2 equilibrium when the North firm chooses to exports in stage 1. Using Lemma 1 and Proposition 1, we can establish the following relationships between the equilibrium outcomes in stage 2 and the strength of IPR protection.

Lemma 2. North firm's profits decline while South firm's profits and aggregate output increase as the strength of IPR weakens in South. These results hold for both modes of North entry into the South market - exports as well as FDI. More formally,

(i) $\pi_{N}^{F}$ and $\pi_{N}^{E}$ are decreasing in $\alpha$.

(ii) $\pi_{S}^{F}$ and $\pi_{S}^{E}$ are increasing in $\alpha$.

(iii) $Q^{E}$ and $Q^{F}$ are increasing in $\alpha$.

As the strength of IPR protection weakens, South firm's investment in absorptive capacity increases. The effective unit cost of production for South, $c_{S} \equiv c(1-\alpha z)$, declines. Part (i) follows from the logic that lower $c_{S}$ leads to higher $q_{S}$, which in turn 
implies lower $q_{N}$ and consequently lower $\pi_{N}$. To understand part (ii), write

$$
\frac{d \pi_{S}}{d \alpha}=\frac{\partial \pi_{S}}{\partial \alpha}+\frac{\partial \pi_{S}}{\partial z} \frac{d z}{d \alpha}
$$

and observe that $\frac{\partial \pi_{S}}{\partial z}=0$ (envelope theorem) and $\frac{\partial \pi_{S}}{\partial \alpha}>0$ (Lemma 1). Part (iii) is easy to understand once we recognize that in a Cournot setup the aggregate output increases as the unit cost declines.

Now we turn to the comparison between $z^{F}$ and $z^{E}$. If IPR protection is perfect, i.e., $\alpha=0$, there is no incentive to invest in absorptive capacity and hence $z^{F}=z^{E}=0$. However, with imperfect IPR protection (i.e., $\alpha>0$ ), absorptive capacity could be lower or higher under FDI. Using (8) and (9) we get

$$
z^{F}-z^{E}=\frac{2 \alpha c(b-2 c)}{\left(9 k^{E}-4 \alpha^{2} c^{2}\right)\left(9 k^{F}-4 \alpha^{2} c^{2}\right)}\left(9\left(k^{E}-k^{F}\right)-\frac{t\left(9 k^{F}-4 \alpha^{2} c^{2}\right)}{b-2 c}\right)
$$

which implies

$$
z^{F} \gtreqless z^{E} \Leftrightarrow t \lesseqgtr \frac{9\left(k^{E}-k^{F}\right)(b-2 c)}{9 k^{F}-4 \alpha^{2} c^{2}} .
$$

That $z^{F}$ could be lower than $z^{E}$ might sound surprising, since the marginal cost of investment in absorptive capacity is lower under FDI. However, the marginal benefit from investment in $z$ under FDI is smaller as well:

$$
\frac{\partial \tilde{\pi}_{S}(\alpha, 0, z)}{\partial z}-\frac{\partial \tilde{\pi}_{S}(\alpha, 1, z)}{\partial z}=-\frac{2 \alpha c t}{9}<0 .
$$

To understand why, note that firm $N$ 's unit cost of production is lower under FDI because it saves trade cost $t$ per unit. The reduction in firm $N$ 's unit cost leads to higher $q_{N}$ and lower $q_{S}$ which in turn reduces firm $S$ 's incentive to invest in $z$. As both marginal benefit and marginal cost of investment in absorptive capacity are lower under FDI, $z^{F}$ could be higher or lower than $z^{E}$. Using (10), Proposition 2 gives a more precise characterization.

PROPOSITION 2. For any given degree of IPR protection, absorptive capacity is strictly higher under FDI than under exports if and only if trade costs are suffciently low. More formally, for all $\alpha \in[0,1]$, there exists a threshold value $\tilde{t}(\alpha) \equiv$ $\min \left\{\frac{9\left(k^{E}-k^{F}\right)(b-2 c)}{9 k^{F}-4 \alpha^{2} c^{2}}, \frac{b}{2}\right\}$ such that $z^{F}>z^{E}$ holds if and only if $t<\tilde{t}(\alpha)$. Furthermore, $\tilde{t}(\alpha)$ is weakly increasing in $\alpha$.

To understand the logic behind Proposition 2, consider the extreme case, $t=0$. As there is no trade cost saving from FDI, North firm's output in the Cournot equilibrium is the same under FDI and exports for a given $z$, as is South firm's output. This in turn implies that South firm's marginal benefit from investment in absorptive capacity is the same under FDI and exports. Since the marginal cost of investment is strictly lower under FDI, it follows that $z^{F}>z^{E}$. By standard continuity argument, it follows that 
$z^{F}>z^{E}$ holds if the trade costs are sufficiently low. Now consider the other extreme when $t$ is almost prohibitive. For exogenously given $z$, South's Cournot output is higher under exports which implies that the marginal benefit of investment in absorptive capacity is higher under exports. If $k^{E} \approx k^{F}$, the marginal cost of investment is similar under FDI and exports, and consequently $z^{E}>z^{F}$ holds. Once again, by continuity argument, it follows that $z^{F}<z^{E}$ holds if the trade costs are sufficiently high.

We conclude this subsection by presenting a non-monotonicity result.

PROPOSITION 3. (i) Absorptive capacity under FDI, $z^{F}$, is inverted U-shaped in firm $S$ 's initial unit cost of production $c$. For all $\alpha \in(0,1]$ there exists $c^{F}(\alpha)>0$ such that

$$
\frac{d z^{F}}{d c} \gtreqless 0 \Leftrightarrow c \lesseqgtr c^{F}(\alpha) .
$$

The absorptive capacity under exports, $z^{E}$, displays similar non-monotonicity with respect to $c$ as long as $t<\min \left\{\frac{b\left(9 k^{E}-\alpha^{2} b^{2}\right)}{9 k^{E}+\alpha^{2} b^{2}}, \frac{b}{2}\right\}$.

(ii) A higher initial unit cost of production does not necessarily imply a higher effective unit cost. More formally, there exist values of $c$, namely $c^{1}$ and $c^{2}$ such that $c^{1}>c^{2}$ and yet $c_{S}^{1} \equiv c^{1}\left(1-\alpha z^{1}\right)<c^{2}\left(1-\alpha z^{2}\right) \equiv c_{S}^{2}$ where $z^{1}$ and $z^{2}$ denote absorptive capacities in stage 2 equilibrium corresponding to initial unit costs $c^{1}$ and $c^{2}$ respectively.

The logic underlying Proposition 3(i) is as follows. Consider the FDI case and suppose $c \approx 0$. The cost difference is very small to start with, and the incremental change in output due to additional investment in $z$ is negligible. If the cost difference is large, $\lim _{c \rightarrow \frac{b}{2}} \tilde{q}_{S}(\alpha, 0, z)=0$ which in turn implies $\lim _{c \rightarrow \frac{b}{2}} \frac{\partial \tilde{\pi}_{S}(\alpha, 0, z)}{\partial z}=0$. Thus, for both extremes - cost difference that is too large or too small - the benefit from an additional unit of investment in $z$ is negligible and consequently $z \approx 0$. For intermediate values of $c$ however $\frac{\partial \tilde{\pi}_{S}(\alpha, 0, z)}{\partial z}$ is strictly positive, which generates the non-monotonicity. Unless the trade cost is large, the same logic works when firm $N$ opts to export.

To understand part (ii), note that, for $c>c^{F}(\alpha)$, investment in absorptive capacity decreases as $c$ increases. Hence, higher $c$ does imply higher $c_{S}$. However, for $c<c^{F}(\alpha)$, absorptive capacity declines as $c$ declines. Thus lower initial marginal cost does not necessarily translate to lower effective marginal cost once investment in absorptive capacity is taken into account. In the Appendix, we show that there are indeed parameterizations under which this occurs. Sawada (2010) finds a similar result in a North-South duopoly model where both North and South firms put effort into reducing its cost. However, IPR protection and location choice, which play an important role in the remainder of this paper, are absent from Sawada (2010).

The finding has an important implication. Suppose there are two South countries, $S_{1}$ and $S_{2}$ which do not trade with each other. Also, assume that the initial marginal cost is lower in $S_{1}$. Despite having an initial cost advantage, firm $S_{1}$ might end up with 
a higher marginal cost, following FDI by a North firm (in both South countries) and the investment in absorptive capacity.

3.4. Exports versus FDI. FDI lowers firm $N$ 's effective unit cost by saving per unit trade cost $t$. However, under FDI, firm $S$ 's unit cost $c_{S} \equiv c(1-\alpha z)$ might be lower if $z^{F}>z^{E}$. So, when does firm $N$ choose to export $(e=1)$ and when does it choose FDI $(e=0)$ ? Assume that in the case of indifference between exports and FDI, firm $N$ opts for FDI. Firm $N$ opts for FDI in SPNE if and only if $\pi_{N}^{F}-\pi_{N}^{E} \geq 0$. We have that

$$
\begin{aligned}
\pi_{N}^{F}-\pi_{N}^{E} \geq 0 & \Leftrightarrow q_{N}^{F}-q_{N}^{E} \geq 0 \\
& \Leftrightarrow \alpha c\left(z^{F}-z^{E}\right)-2 t \leq 0 .
\end{aligned}
$$

where the first $\Leftrightarrow$ follows from using that $\pi_{N}^{F}=\left(q_{N}^{F}\right)^{2}, \pi_{N}^{E}=\left(q_{N}^{E}\right)^{2}$, and the second $\Leftrightarrow$ follows from substituting the expression for $q_{N}^{F} \equiv \tilde{q}_{N}\left(\alpha, 0, z^{F}\right)$ and $q_{N}^{E} \equiv \tilde{q}_{N}\left(\alpha, 0, z^{E}\right)$ in (11).

First, consider the case $\alpha=0$. IPR protection is perfect which implies $z^{F}=z^{E}=0$. Firm $N$ chooses FDI for all $t>0$ since $\alpha c\left(z^{F}-z^{E}\right)-2 t=-2 t<0$. In the case of perfect IPR protection, firm $N$ 's only consideration (while making location choice) is trade costs. By choosing FDI, firm $N$ avoids trade costs and hence it prefers FDI to exports.

Now consider the case $t=0$. From (8) and (9) we know that $z^{F}-z^{E}>0$ which implies that $\alpha c\left(z^{F}-z^{E}\right)-2 t>0$. In the case of zero trade costs, firm $N$ 's unit cost is the same no matter where it locates, but firm $S$ 's unit cost $c_{S} \equiv c(1-\alpha z)$ is higher if firm $N$ chooses to export. Thus firm $N$ 's optimal choice is to locate in North and export to South.

The discussion above casts the trade-off involved in firm $N$ 's location choice in terms of trade costs and absorptive capacity. However, note that, absorptive capacity is an endogenous variable. The equilibrium value of absorptive capacity depends on trade cost parameter, $t$, and the degree of IPR protection, $\alpha$ - see (8) and (9). Substituting the expression for $z^{F}$ and $z^{E}$ from (8) and (9) in (11) above and analyzing the inequality further gives the following proposition.

PROPOSITION 4. The North firm prefers FDI to exports if IPR protection is strong enough. The minimum degree of IPR protection that induces FDI increases as trade costs decline. More formally, for all $t>0$, there exists $\alpha(t) \in[0,1]$ such that firm $N$ opts for FDI in stage 1 if and only if $\alpha \leq \alpha(t)$. There exists $\bar{t} \equiv$ $\min \left\{\frac{9 c^{2}\left(k^{E}-k^{F}\right)(b-2 c)}{\left(9 k^{F}-4 c^{2}\right)\left(9 k^{E}-3 c^{2}\right)}, \frac{b}{2}\right\}$ such that $\alpha(0)=0, \alpha(t)<1$ for $t<\bar{t}$ and $\alpha(t)=1$ for $t \geq \bar{t}$. Furthermore, $\alpha(t)$ is continuous (in $t$ ) and $\alpha^{\prime}(t)>(=) 0$ for all $t<(>) \bar{t}$.

Proposition 4 says how the exports versus FDI decision of firm $N$ depends on trade costs and the strength of IPR protection in South. Assume that $\bar{t}=\frac{9 c^{2}\left(k^{E}-k^{F}\right)(b-2 c)}{\left(9 k^{F}-4 c^{2}\right)\left(9 k^{E}-3 c^{2}\right)}$. 
In that case, according to Proposition 4 , the North firm locates in South for all $t \in\left(\bar{t}, \frac{b}{2}\right)$ even if there is no protection of IPR in South. This finding reflects the tariff-jumping motive of FDI, except that we use trade costs instead of tariffs. To ensure that motive dominates - at least for the high values of trade costs - we assume that the following condition holds for the remainder of section $3:{ }^{7}$

$$
k^{F}>\frac{b^{2}}{27}+\frac{2}{3} k^{E} \text {. }
$$

As firm $N$ might locate in South even if there is no protection of IPR (i.e., $\alpha=1$ ), it might seem that endogenous absorptive capacity and consequently the strength of IPR protection has little role to play. However, note that if absorptive capacity were exogenous and the same under FDI and exports (i.e., $z=z^{F}=z^{E}$ ), (11) implies that firm $N$ would prefer FDI for all $t>0$ and not just high $t$. This observation highlights the importance of endogenous absorptive capacity in firm $N$ 's choice between FDI versus exports.

The second part of the Proposition unravels a complementary relationship between trade liberalization and South's IPR protection. As trade costs decline, the option of exports becomes more attractive to North. This implies that the critical level of IPR protection needs to be stronger in South so that the North firm prefers FDI to exports. As we show below, the impact of IPR protection on North firm's location decision plays an important role in determining the optimal IPR policy for South.

3.5. Intellectual Property Rights (IPR). Consider an extended game where in Stage 0, prior to location choice of firm $N$, the South government chooses $\alpha$ to maximize South welfare. Would it ever choose $\alpha \in(0,1)$ ? In other words, would South welfare ever be higher with some protection of IPR? ${ }^{8}$

South welfare $(W)$ is the sum of consumer surplus $(C S)$ and South firm's profits $\left(\pi_{S}\right)$. Corresponding to the demand function $P=b-Q$, consumer surplus $(C S)$ is $Q^{2} / 2$. Let $C S^{F}(\alpha)$ and $W^{F}(\alpha)$ respectively denote the consumer surplus and welfare when firm $N$ chooses FDI in stage 1 . Similarly define $C S^{F}(\alpha)$ and $W^{F}(\alpha)$ when firm $N$ chooses exports. By definition,

$$
W^{g}(\alpha)=C S^{g}(\alpha)+\pi_{S}^{g}(\alpha) ; g \in\{E, F\} .
$$

For a given $\alpha$, South welfare $(W)$ is $W^{F}(\alpha)$ if firm $N$ chooses FDI and $W^{E}(\alpha)$ if firm $N$ chooses exports. Since Firm $N$ chooses FDI for $\alpha \leq \alpha(t)$ we have that

$$
W=\left\{\begin{array}{l}
W^{F}(\alpha) \text { if } \alpha \leq \alpha(t) \\
W^{E}(\alpha) \text { if } \alpha>\alpha(t)
\end{array} .\right.
$$

${ }^{7}$ Equation (12) ensures that $\frac{9 c^{2}\left(k^{E}-k^{F}\right)(b-2 c)}{\left(9 k^{F}-4 c^{2}\right)\left(9 k^{E}-3 c^{2}\right)}<\frac{b}{2}$.

${ }^{8}$ We are primarily interested in South's incentive to protect IPR. North always prefers stronger IPR protection in South because it leads to higher profit for the North firm (see Proposition 2). Since, in our framework, North welfare consists solely of the North firm's profit in South, its welfare is maximized when IPR protection in South is full, i.e. $\alpha=0$. 
South welfare under FDI, $W^{F}$, increases as $\alpha$ increases since both $C S^{F} \equiv\left(Q^{F}\right)^{2} / 2$ and $\pi_{S}^{F}$ are increasing in $\alpha$ (Lemma 2). South welfare under exports, $W^{E}$, increases with $\alpha$ for analogous reasons. Given the relationship between $W^{E}, W^{F}$ and $\alpha$, it immediately follows that the optimal $\alpha$ for South is either 1 or $\alpha(t)$ (which can be 1 for some parameter values). Thus the South government either offers no protection $(\alpha=1)$ or just enough $(\alpha=\alpha(t))$ so that the North firm opts for FDI in South. The proposition below provides a sharper characterization.

PROPOSITION 5. For a given trade cost $t \geq 0$, let $\alpha^{*}(t)$ denote the level of IPR protection that maximizes South welfare. The relationship between $t$ and $\alpha^{*}(t)$ is nonmonotone. More formally, there exists $t_{1}$ and $t_{2}$ satisfying $0<t_{1} \leq t_{2}<\bar{t}<\frac{b}{2}$ such that $\alpha^{*}(t)=1$ for $t<t_{1}$ and $t \geq \bar{t}$ while $\alpha^{*}(t)=\alpha(t)<1$ for $t \in\left(t_{2}, \bar{t}\right)$. Furthermore, $\alpha^{*}(t)$ is strictly increasing in $t$ for all $t \in\left(t_{2}, \bar{t}\right)$.

Proposition 5 says that if the trade costs are too high or too low, South does not have any incentive to protect IPR. For a range of intermediate values of trade costs, some protection of IPR is optimal. Consider first $t \geq \bar{t}$. From Proposition 4 , we know that, for those high values of trade costs, firm $N$ undertakes FDI irrespective of the strength of IPR protection. Thus $W=W^{F}(\alpha)$ for all $\alpha \in[0,1]$. As North firm's location choice is not affected by $\alpha$ and $W^{F}(\alpha)$ is increasing in $\alpha$ it immediately follows that $\alpha^{*}()=$. for $t \geq \bar{t}$.

Now consider the other extreme: $t=0$. Proposition 4 says that $\alpha(0)=0$ which implies that firm $N$ undertakes FDI only if IPR in South is fully protected. Thus $W=W^{F}(\alpha)$ for $\alpha=0$ and $W=W^{E}(\alpha)$ for $\alpha \in(0,1]$. Suppose $\alpha=0$, i.e., IPR is fully protected. Then there is no incentive to invest in absorptive capacity. Since $t=0$ and $z^{E}=z^{F}=0$, South welfare under exports and FDI regime are identical; $W^{E}(0)=W^{F}(0)$. Now for any increase in $\alpha$ from zero, firm $N$ opts for exports. Since $W^{E}(\alpha)$ is continuous and strictly increasing in $\alpha$ it follows that welfare is maximized by setting $\alpha=1$. Thus, as in the case of high trade costs, we find that no protection is optimal when $t=0$. Standard continuity argument implies that there exists $t_{1}>0$ such that no protection of IPR continues to optimal for $t<t_{1}$.

For intermediate values of $t$, i.e. $t \in\left(t_{1}, \bar{t}\right)$, taking account of location decision by firm $N$, we get $W=W^{F}(\alpha)$ for $\alpha \in[0, \alpha(t)]$ and $W=W^{E}(\alpha)$ for $\alpha \in(\alpha(t), 1]$. As both $W^{E}(\alpha)$ and $W^{F}(\alpha)$ are increasing in $\alpha$, the choice of optimal degree of IPR protection effectively reduces to the comparison between $W^{F}(\alpha(t))$ and $W^{E}(1)$. In the Appendix, we show that $\lim _{t \rightarrow \bar{t}}\left[W^{F}(\alpha(t))-W^{E}(1)\right]>0$. This implies that there exists a range of trade costs, $t \in\left(t_{2}, \bar{t}\right)$, such that $\alpha^{*}(t)=\alpha(t)$. For those values of $t$, the South government finds it optimal to offer some IPR protection, in fact, just enough to attract FDI. As the trade costs decline, exports become more attractive for firm $N$. Attracting FDI requires more protection of IPR from South which explains the last part of Proposition 5: $\alpha^{*}(t)$ is strictly decreasing in $t$. 
3.6. Discussion. We have made several simplifying assumptions for tractability. Here, we briefly explore what happens when we relax some of those assumptions.

3.6.1. Enforcement costs. We have assumed that the South government does not incur any costs for enforcing IPR. Adding enforcement costs to the model does not qualitatively affect our results. Let $G(\alpha)$ denote the cost of enforcing $\alpha$ where $G(\alpha)$ is continuous and strictly decreasing in $\alpha$ and $G(1)=0$. This specification captures the idea that, except for the case of no IPR protection, enforcement is costly and this cost increases as the degree of IPR protection (to be enforced) increases. Taking enforcement costs into account we can write South welfare $(W)$ as

$$
W=\left\{\begin{array}{l}
W^{F}(\alpha)-G(\alpha) \text { if } \alpha \leq \alpha(t) \\
W^{E}(\alpha)-G(\alpha) \text { if } \alpha>\alpha(t)
\end{array} .\right.
$$

Since $W^{g}(\alpha)(g \in\{E, F\})$ is strictly increasing in $\alpha$ and $G(\alpha)$ is strictly decreasing in $\alpha$, it follows that welfare maximizing $\alpha$ continues to be either $\alpha(t)$ or 1 . However, the presence of costly enforcement shrinks the range of parameterizations where some IPR protection occurs in equilibrium.

3.6.2. Tariffs versus Transportation Costs. Implicitly, we have treated trade costs as transportation costs which involve loss of resources (as in Brander and Krugman, 1981). Except for subsection 3.5 (where we consider South welfare), the analysis and the results remain unchanged if we interpret $t$ as tariff rather than trade cost. Incorporating tariff revenues in welfare function does not affect the non-monotone relationship between $t$ and $\alpha$ highlighted in Proposition 5.

When the tariff rate is zero or prohibitive, tariff revenues do not matter. For both these cases - which correspond to zero trade costs and prohibitive trade costs in the previous section - it remains optimal for South to offer no IPR protection at all. For intermediate values of $t$, the FDI option becomes less attractive for South. Welfare under FDI remains same as before, whereas welfare under exports is higher because of tariff revenues. Thus the range of values for which optimal $\alpha^{*} \in(0,1)$ as well as the value of $\alpha^{*}$ will generally be different when we treat $t$ as per unit tariff instead of trade cost. Nevertheless, the non-monotonicity remains.

3.6.3. Multiple firms. A natural step is to extend the analysis to incorporate multiple firms in both countries - North and South.

Adding more firms in South is conceptually straightforward. Suppose, as in the main model, there is one North firm $N$ but two South firms - firm $S^{1}$ and firm $S^{2}$ with unit costs $c^{1}$ and $c^{2}$ respectively. Firm $S^{l}$ can reduce its unit cost to $c^{l}\left(1-\alpha z^{l}\right)$ where $l=1,2$ and $z^{l}$ is firm $S^{l}$ 's chosen level of absorptive capacity. The algebra is tedious as it involves three firms with three different unit costs but substantive qualitative changes are unlikely. 
Adding more North firms in the current setup requires some modification. Suppose there is one South, firm $S$, with initial unit cost $c$ and two North firms $N^{1}$ and $N^{2}$ with zero unit cost. Stage 1 of the model described in 3.1 involves unilateral decision making by firm $N$ regarding the choice exports versus FDI. Here, firms $N^{1}$ and $N^{2}$ will compete strategically for the choice between exports and FDI. In particular, whether firm $N^{l}$ will choose FDI will depend on whether firm $N^{h}$ chooses FDI or not $(l, h=$ $1,2, l \neq h)$. Some modification is also needed in modeling South firm's investment in absorptive capacity. Imitation for the South firm is presumably easier when both firms $N^{1}$ and $N^{2}$ choose FDI as opposed to when only one North firm chooses FDI. Thus, in addition to $k^{E}$ and $k^{F}$, investment cost parameter $k$ will take an additional value $k^{E F} \in\left(k^{F}, k^{E}\right)$ which applies when exactly one firm, $N^{1}$ or $N^{2}$, chooses FDI. For a range of parameterizations, there will be two threshold values of $\alpha$ - say, $\alpha_{1}$ and $\alpha_{2}$ - such that both North firms choose FDI if $\alpha<\alpha_{1}$, exactly one firm chooses FDI if $\alpha_{1}<\alpha<\alpha_{2}$ and both firms choose exports if $\alpha>\alpha_{2}$. While the analysis will be involved in this case the spirit of the analysis will be the same as before. The South government will choose $\alpha_{1}, \alpha_{2}$ or 1 as the optimal $\alpha$ depending on whether it wants both North firms, one North firm, or no North firm to choose FDI.

\section{MASKING}

We have shown that strengthening IPR protection can improve South welfare by affecting the location choice of the North firm. However, in two extreme but important cases considered in the trade literature - free trade and prohibitive tariffs - location choice is invariant to the IPR policy. Under free trade, FDI does not save any trade costs because there is no costs to save. The North firm is better off by opting for exports because imitation is more costly for the South firm under exports. If tariffs are prohibitive, clearly, the North firm always opts for FDI. In those cases, where location choices are pre-determined by other factors, can some protection of IPR be optimal for South? According to our model in the previous section, the answer is no. As we show below, however, the answer can change once we introduce the possibility of masking. Whether trade costs are zero or prohibitive, South may have an incentive to protect IPR.

For the remainder of this section, we consider the case where $t=0$ and firm $N$ always chooses exports. ${ }^{9}$ As location choice is unaffected by the strength of IPR protection, we assume away that stage. Suppose prior to firm $S$ 's investment in absorptive capacity, firm $N$ hinders firm $S$ from imitating technology by undertaking a variety of costly activities such as creating software programming traps, encrypting important codes, or using special material to make imitation difficult. We use masking to denote all such activities. Masking raises firm $N$ 's unit $\operatorname{cost}$ from $c_{N}=0$ to $c_{N}=m$. At the same

\footnotetext{
${ }^{9}$ The analysis is analogous when $t$ is prohibitive and firm $N$ chooses FDI.
} 
time, it increases firm $S^{\prime}$ 's cost of investment in absorptive capacity. In the absence of masking, firm $S^{\prime}$ 's cost of investment is $k$ while it becomes $k^{M}>k$ under masking.

The timing of the events is as follows:

Stage 1 [Masking decision]: Given the degree of IPR protection $\alpha$, firm $N$ determines whether or not to engage in masking. Let $d$ denote the binary variable capturing the masking decision by firm $N$ :

$$
d=\left\{\begin{array}{l}
1, \text { if firm } N \text { masks its technology } \\
0, \text { otherwise }
\end{array}\right.
$$

Stage 2 [Investment in absorptive capacity]: Given $\alpha$ and $d$, firm $S$ chooses the level of absorptive capacity $z$.

Stage 3 [Cournot competition]: Given $\alpha, d$, and $z$, each firm $i$ chooses $q_{i}$ to maximize its profits taking rival firm's output, $q_{j}$, as given $(i, j \in\{N, S\}, i \neq j)$.

The Cournot equilibrium in stage 3 is now given by

$$
\begin{gathered}
\tilde{q}_{N}(\alpha, d, z)=\frac{b-2 d m+c(1-\alpha z)}{3}, \quad \tilde{q}_{S}(\alpha, d, z)=\frac{b-2 c(1-\alpha z)+d m)}{3}, \\
\tilde{\pi}_{N}(\alpha, d, z)=\frac{(b-2 d m+c(1-\alpha z))^{2}}{9}, \quad \tilde{\pi}_{S}(\alpha, d, z)=\frac{(b-2 c(1-\alpha z)+d m)^{2}}{9} .
\end{gathered}
$$

For given $\alpha, d$, firm $S$ 's absorptive capacity in stage 2 is

$$
z=\frac{2 \alpha c(b-2 c+d m)}{9 k(d)-4 \alpha^{2} c^{2}} \equiv z(\alpha, d)
$$

Observe that outputs and profits in stage 2 equilibrium and absorptive capacity in stage 3 equilibrium are exactly the same as those obtained in section 3 once we write $d=$ $e$ and $m=t$. Then, in fact, the game in this section is equivalent to the game described in section 3 . Whether firm $N$ masks or not in this game is effectively based on the same calculations that determine whether firm $N$ exports or not in the game described in section 3. As we found, contrary to expectation, that equilibrium absorptive capacity might be higher under exports, here also, we find that absorptive capacity might be higher under masking. Masking increases the marginal cost of investment in absorptive capacity which discourages investment. At the same time, masking increases firm $N$ 's unit cost by $m$ which raises rival firm $S$ 's output and encourages firm $S$ to invest in absorptive capacity. Thus absorptive capacity might be higher or lower under masking. This result is similar in spirit to Proposition 2 where we showed that absorptive capacity might be higher or lower under FDI.

When will firm $N$ engage in masking in stage 1 ? If IPR protection is perfect, i.e., $\alpha=0$, firm $S$ has no incentive to invest in absorptive capacity irrespective of the masking decision. As its technology is fully protected by IPR policy, firm $N$ does not 
have any incentive to mask its technology. The following result follows from invoking standard continuity argument. ${ }^{10}$

Lemma 3. Firm $N$ does not mask its technology if IPR protection in South is strong enough. More formally, for all $m>0$, there exists $\alpha(m) \in[0,1]$ such that firm $N$ chooses not to mask in stage 1 if and only if $\alpha \leq \alpha(m)$.

Now we are ready to examine the IPR policy. For any given choice of firm $N$ in stage 1 - masking $(d=1)$ or non-masking $(d=0)$ - weakening IPR protection reduces the unit cost of production for firm $\mathrm{S}$ which in turn implies higher consumer surplus as well as higher profits for firm S. Thus, IPR protection does not play any role unless it affects the masking decision. If $m$ is large, firm $N$ will not mask anyway, while if $m$ is small, firm $N$ will always mask. Thus, South's IPR policy affects the masking decision only for the intermediate values of $m$. By inducing firm $N$ not to mask, the South government can improve South welfare. The following proposition can be obtained. ${ }^{11}$

PROPOSITION 6. For a given $m \geq 0$, let $\alpha^{*}(m)$ denote the level of IPR protection that maximizes South welfare. The relationship between $m$ and $\alpha^{*}(m)$ is non-monotone. There exist $m_{1}, m_{2}$ and $m_{3}$ satisfying $0<m_{1} \leq m_{2}<m_{3}<\infty$ such that

$$
\alpha^{*}(m)=\left\{\begin{array}{cc}
1 & \text { if } m<m_{1} \\
\alpha(m) \in(0,1) & \text { if } m \in\left[m_{2}, m_{3}\right] . \\
1 & \text { if } m>m_{3}
\end{array} .\right.
$$

\section{LiCENSING}

In our basic model, FDI is the only mode for firm $N$ to serve South with prohibitive trade costs. Then the South government has an incentive to set $\alpha=1$ to facilitate imitation which reduces the production cost of firm $S$ and increases consumer surplus. However, anticipating imitation, firm $N$ might license and transfer its technology to firm $S$. In this section, we introduce licensing into our framework and show that strengthening IPR protection may strictly improve South welfare by inducing licensing.

To focus on the comparison between FDI and licensing, we abstract from the option of exports. This is the case if trade costs are prohibitive. Furthermore, we assume that in the case of licensing, the efforts to transfer technology are not made by firm $S$ but by firm $N$. Specifically, prior to competing in the product market, firm $N$, by incurring a fixed cost $L>0$, can license its zero-cost technology to firm $S$ for an upfront fixed fee $F \geq 0 .{ }^{12}$ We assume that $L<b^{2} / 45$ where $b$ is the intercept term in (1). This

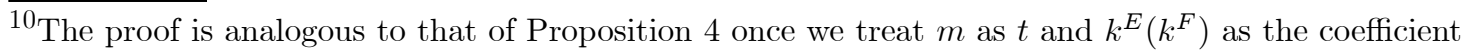
in the cost function, $C(z)=k z^{2}$ in case of masking (non-masking).

${ }^{11}$ The proof as well as the logic underlying Proposition 6 is similar to that corresponding to Proposition 5 and hence is omitted.

${ }^{12}$ Yang and Maskus (2009) mention "a lump-sum license fee without per-unit royalties captures the empirical reality that a large portion of technology contracts in developing countries have this feature."
} 
upper bound on $L$ ensures that licensing occurs for some parameterizations. Firm $N$ cannot commit not to produce after licensing has taken place. Thus, with or without licensing, the relevant market structure is duopoly. ${ }^{13}$ This implies that firm $N$ builds a plant in South in both cases. Both firms $N$ and $S$ enjoy zero unit cost in the case of licensing. Whereas firm $N$ 's unit cost is 0 , firm $S$ 's unit cost is $c(1-\alpha z)$ in the case of FDI. Note that absorptive capacity $z \in[0,1]$ matters only in the case of FDI and is exogenously given. This implies that the first two stages of the game in section 3.1 - location choice and investment in absorptive capacity - are absent. As before, the inverse demand is given by $P=b-\left(q_{N}+q_{S}\right)$.

We have a 2 -stage game with licensing decision followed by product market competition. Let $u$ denote the binary variable capturing the licensing decision:

$$
u=\left\{\begin{array}{l}
0, \text { if licensing takes place } \\
1, \text { otherwise }
\end{array}\right.
$$

Cournot outcomes in stage 2 are given by

$$
\begin{aligned}
& \tilde{q}_{N}(\alpha, u)=\frac{b+u c(1-\alpha z)}{3}, \quad \tilde{q}_{S}(\alpha, u)=\frac{b-2 c u(1-\alpha z)}{3}, \\
& \tilde{\pi}_{N}(\alpha, u)=\frac{(b+c u(1-\alpha z))^{2}}{9}, \quad \tilde{\pi}_{S}(\alpha, u)=\frac{(b-2 c u(1-\alpha z))^{2}}{9} .
\end{aligned}
$$

In Stage 1, i.e., the licensing stage, we assume that firm $N$ makes a take-it-or-leave-it offer to firm $S$. Firm $N$ incurs $L$ with licensing:

$$
\begin{aligned}
& \pi_{N}(\alpha, 0)=\frac{b^{2}}{9}-L+F, \pi_{S}(\alpha, 0)=\frac{b^{2}}{9}-F \\
& \pi_{N}(\alpha, 1)=\frac{(b+c(1-\alpha z))^{2}}{9}, \pi_{S}(\alpha, 1)=\frac{(b-2 c(1-\alpha z))^{2}}{9} .
\end{aligned}
$$

The upfront fixed licensing fee is given by

$$
F=\tilde{\pi}_{S}(\alpha, 0)-\tilde{\pi}_{S}(\alpha, 1)=\frac{4 c(1-\alpha z)(b-c(1-\alpha z))}{9},
$$

whenever licensing occurs in equilibrium, i.e., whenever the joint profits are higher under licensing:

$$
\begin{aligned}
& \pi_{N}(\alpha, 0)+\pi_{S}(\alpha, 0) \geq \pi_{N}(\alpha, 1)+\pi_{S}(\alpha, 1) \\
\Leftrightarrow & c(1-\alpha z)(2 b-5 c(1-\alpha z))-9 L \geq 0 \\
\Leftrightarrow & c(1-\alpha z) \in\left[c_{1}, c_{2}\right],
\end{aligned}
$$

where $c_{1} \equiv \frac{b-\sqrt{b^{2}-45 L}}{5}$ and $c_{2} \equiv \frac{b+\sqrt{b^{2}-45 L}}{5}$.

Decomposing (13) further provides a more comprehensive picture of licensing which is articulated in the following Lemma.

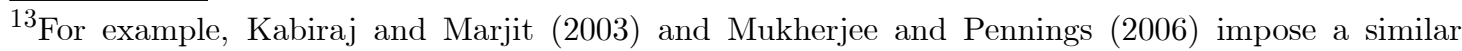
assumption.
} 
Lemma 4. (i) If $c<c_{1}$ or $c>\frac{c_{2}}{1-z}$ licensing does not occur in equilibrium irrespective of $\alpha$.

(ii) If $c \in\left[c_{1}, \frac{c_{1}}{1-z}\right]$ licensing occurs if and only if $\alpha \leq \tilde{\alpha}_{1}(c) \equiv \frac{1}{z}\left(1-\frac{c_{1}}{c}\right)$.

(iii) If $c \in\left[\frac{c_{1}}{1-z}, c_{2}\right]$ licensing occurs for all $\alpha$.

(iv) If $c \in\left[c_{2}, \frac{c_{2}}{1-z}\right]$ licensing occurs if and only if $\alpha \geq \tilde{\alpha}_{2}(c) \equiv \frac{1}{z}\left(1-\frac{c_{2}}{c}\right)$.

Lemma 4(i) says that licensing occurs when firm $S$ 's initial unit cost $c$ is not too high or not too low. If $c$ is too high then firm $N$ does not want to relinquish its almostmonopoly position by licensing its zero-cost technology to firm S. If $c$ is too low then incurring $L$ is not worthwhile for firm $N$. For intermediate values of $c$ licensing takes place.

Consider parameterizations in Lemma 4 (ii): $c_{1}<c<\frac{c_{1}}{1-z}$. If there is no IPR protection (i.e., $\alpha=1$ ), then we have $c(1-\alpha z)=c(1-z)<c_{1}$, where the inequality follows from $c_{1}<c<\frac{c_{1}}{1-z}$. In view of (13), therefore, licensing does not occur. However, if IPR protection is perfect (i.e., $\alpha=0$ ), then $c(1-\alpha z)=c>c_{1}$ holds and hence licensing takes place. This suggests that, for parameterizations considered in Lemma 4 (ii) licensing occurs in equilibrium if IPR protection is strong enough. Exactly the opposite holds for $c_{2}<c<\frac{c_{2}}{1-z}$. If IPR protection is perfect, then we have $c(1-\alpha z)=$ $c>c_{2}$ with $c_{2}<c<\frac{c_{2}}{1-z}$ and it follows from (13) that licensing does not occur. However, in absence of any IPR protection $c(1-\alpha z)=c(1-z)<c_{2}$ and licensing occurs. Thus, here licensing occurs if IPR is weak enough. In the intermediate range $c \in\left[\frac{c_{1}}{1-z}, c_{2}\right]$, it is easy to show that no matter what $\alpha$ is licensing takes place.

Let us now turn to welfare. South welfare under licensing and no-licensing respectively are

$$
\begin{aligned}
W^{L}(\alpha) & =\frac{2 b^{2}}{9}+\frac{(b-2 c(1-\alpha z))^{2}}{9}, \\
W^{F}(\alpha) & =\frac{(2 b-c(1-\alpha z))^{2}}{18}+\frac{(b-2 c(1-\alpha z))^{2}}{9},
\end{aligned}
$$

where the first term in the welfare expression is consumer surplus and the second term is product market profits less fixed fee $F$ (if any). The second term in the two welfare expressions are the same since firm $N$ makes a take-it-or-leave-it offer to firm $S$. That is, firm $N$ offers firm $S$ just enough so that firm $S$ is indifferent between licensing and no-licensing. Consumer surplus is larger with licensing than with FDI. This is because, in the case of licensing, both firms $N$ and $S$ enjoy zero unit cost and hence the goods price is lower. Thus, $W^{L}(\alpha)>W^{F}(\alpha)$ holds.

Let $\alpha^{*}$ denote the value of $\alpha$ that maximizes South welfare. Consider first $c<c_{1}$ or $c>\frac{c_{2}}{1-z}$. For such parameter values licensing does not occur for any $\alpha$. Thus, welfare is given by $W^{F}(\alpha)$ which is maximized at $\alpha=1$ because it is increasing in $\alpha$. Now consider $c \in\left[\frac{c_{1}}{1-z}, c_{2}\right]$ for which licensing occurs irrespective of $\alpha$. Here, welfare is given by $W^{L}(\alpha)$ which is strictly increasing in $\alpha$ and hence maximized at $\alpha=1$. Thus, 
$\alpha^{*}=1$ whenever $c<c_{1}$, or $c>\frac{c_{2}}{1-z}$ or $c \in\left(\frac{c_{1}}{1-z}, c_{2}\right)$. Indeed, for $c \in\left(c_{2}, \frac{c_{2}}{1-z}\right), \alpha^{*}=1$ as well. To see why, note that licensing occurs $\alpha \geq \tilde{\alpha}_{2}(c) \equiv \frac{1}{z}\left(1-\frac{c_{2}}{c}\right)$ [see Lemma 4(iv)]. Thus, licensing occurs when $\alpha=1$. Then the claim $\alpha^{*}=1$ follows from noting that $W^{L}(1)>W^{F}(1)$ and both $W^{L}(\alpha)$ and $W^{F}(\alpha)$ are increasing in $\alpha$.

The discussion above suggests that $\alpha^{*}<1$ can hold only if $c \in\left(c_{1}, \frac{c_{1}}{1-z}\right)$. For such parameterizations licensing occurs if and only if $\alpha \leq \tilde{\alpha}_{1}(c) \equiv \frac{1}{z}\left(1-\frac{c_{1}}{c}\right)$. The South government could choose $\alpha=\tilde{\alpha}_{1}(c)$ and ensure licensing or it could choose $\alpha=1$ in which case licensing does not take place. Our last proposition confirms indeed the welfare maximizing South government would choose $\alpha=\tilde{\alpha}_{1}(c)$ for a subset off $c \in\left(c_{1}, \frac{c_{1}}{1-z}\right)$ and ensure that licensing takes place. ${ }^{14}$

PROPOSITION 7. Let $\alpha^{*}(c)$ denote the level of IPR protection that maximizes South's welfare. The relationship between $c$ and $\alpha^{*}(c)$ is non-monotone. There exist $c_{3}$ satisfying $c_{1} \leq c_{3}<\frac{c_{1}}{1-z}$ such that

$$
\alpha^{*}(c)=\left\{\begin{array}{cc}
1 & \text { if } c<c_{3} \\
\tilde{\alpha}_{1}(c) \in(0,1) & \text { if } c \in\left[c_{3}, \frac{c_{1}}{1-z}\right] . \\
1 & \text { if } c>\frac{c_{1}}{1-z}
\end{array} .\right.
$$

The following should be noted. In our basic model, firm $N$ will serve South through exports under free trade. Then the South government has an incentive to set $\alpha=1$ to facilitate imitation. If licensing becomes an option for firm $N$ to serve South in this situation, we can make a similar comparison between exports and licensing. We can easily verify that the results are qualitatively the same. That is, strengthening IPR protection may strictly enhance South welfare by inducing licensing.

\section{Concluding Remarks}

We examined South's incentives to protect IPR in an environment where the strength of IPR protection in South has no bearing on North firm's incentives to innovate. In the presence of (i) endogenous absorptive capacity and (ii) North firm's location choice both endogenously determined in our framework-, we found that South can benefit from having strict IPR protection depending on the level of trade costs. We also found that the relationship between the optimal strength of IPR protection in South and trade costs is non-monotone. If the trade costs are too high or too low, there is no incentive to protect IPR in South. For moderate values of trade costs, however, it is optimal for South to protect IPR to some extent. In this range of values for trade costs, the IPR protection becomes stronger as the trade costs decline.

We specifically extended our basic model into two directions. We introduced the possibility of North's masking technology in one extension and the possibility of North's licensing in the other. We showed that in the presence of masking or licensing, some

\footnotetext{
${ }^{14}$ The proof is similar to that of Proposition 5 and hence is omitted.
} 
protection of IPR might be optimal for South even if the trade costs are zero or prohibitive.

Our analysis also offers an explanation for the ambiguous relationship between FDI and spillovers which is often observed in the data. Key to our explanation is the role of absorptive capacity. Under FDI, absorption is less costly but the South firm faces stronger competition since the North firm saves trade costs when it opts for FDI. As a consequence, we found that absorptive capacity/spillovers can be higher or lower under FDI.

Note that a common theme across all three stories referred to in this paper -FDI, masking, and licensing - is that IPR protection improves South welfare by inducing a switch of regimes: from exports to FDI in section 3, from masking to non-masking in section 4 , and from no licensing to licensing in section 5. To highlight these channels clearly, we have focused on the case of an international duopoly (i.e., a single firm in each country). This setup or an extension of this setup with a few oligopolistic firms captures important part of reality but it also results in lots of discontinuities which complicates the analysis. An alternative is to consider monopolistic competition with fixed number of firms.

Furthermore, throughout the paper, we have focused on a 2-country model where a North firm locates in South to serve South consumers. Motta and Norman (1996), Ekholm, Forslid and Markusen (2007) and most recently Tintelnot (2017) have pointed out that North firms locate in South not necessarily to serve South consumers but to serve consumers in other export markets, i.e., use South as an export platform. Trade liberalization in such environments can have nuanced effect on IPR policies. If North faces lower tariffs from South, exports might become more attractive. On the other hand, if South faces lower tariffs from other export markets, FDI becomes more attractive. Extent of tariff reductions as well as differences in market size will play an important role in determining the effect of trade liberalization on IPR protection. Both issues: monopolistic competition and export-platform FDI are left for future research. 


\section{APPENDix}

Proof of Lemma 2: (i) Using (5) and (7) we get

$$
\pi_{N}^{F}=\tilde{\pi}_{N}(\alpha, 0, z(\alpha, 0))=\frac{(b+c(1-\alpha z(\alpha, 0)))^{2}}{9} .
$$

By Proposition 1(i), $z(\alpha, 0)$ is increasing in $\alpha$. This implies that $c_{S}=c(1-\alpha z(\alpha, 0))$ is decreasing in $\alpha$ which in turn implies that $\pi_{N}^{F}$ decreases as $\alpha$ increases. The proof is analogous for $\pi_{N}^{E}$.

(ii) See the paragraph after Lemma 2 in the text.

(iii) Using (4) and (7) we get $Q^{F}=\frac{2 b-c(1-\alpha z(\alpha, 0))}{3}$ and $Q^{E}=\frac{2 b-t-c(1-\alpha z(\alpha, 1))}{3}$. Then, applying the argument presented in the proof of (i) gives the results.

Proof of Proposition 2: The first part of the proof essentially restates (10). That $\tilde{t}(\alpha)$ is increasing in follows directly from observing the expression of $\tilde{t}(\alpha)$ in first part of the Proposition.

Proof of Proposition 3: (i) Differentiating $z(\alpha, e)$ with respect to $c$, we get:

$$
\frac{d z(\alpha, e)}{d c}=\frac{2 \alpha\left[4 \alpha^{2} b c^{2}+\left(8 \alpha^{2} e t-36 k(e)\right) c+9 k(e)(b+e t)\right]}{\left(9 k(e)-4 \alpha^{2} c^{2}\right)^{2}} .
$$

Consider $z^{F}=z(\alpha, 0)$. For all $\alpha>0, \lim _{c \rightarrow 0} \frac{d z(\alpha, 0)}{d c}=\frac{2 \alpha b}{9 k^{F}}>0$ while $\lim _{c \rightarrow \frac{b}{2}} \frac{d z(\alpha, 0)}{d c}=$ $-\frac{2 \alpha b}{9 k^{F}-\alpha^{2} b^{2}}<0$. These limit values together with the fact that $4 \alpha^{2} b c^{2}-36 k(e) c+9 k(e) b$ is quadratic in $c$ imply that there exists a unique $c^{F}(\alpha) \in\left(0, \frac{b}{2}\right)$ such that $\frac{d z(\alpha, 0)}{d c} \gtreqless$ $0 \Leftrightarrow c \lesseqgtr c^{F}(\alpha)$. Now consider $z^{E}=z(\alpha, 1)$. We have that $\lim _{c \rightarrow 0} \frac{d z(\alpha, 1)}{d c}=\frac{2 \alpha(b+t)}{9 k^{E}}>0$ and $\lim _{c \rightarrow \frac{b}{2}} \frac{d z(\alpha, 0)}{d c}=-\frac{2 \alpha\left(9 k^{E}+\alpha^{2} b^{2}\right)}{\left(9 k^{E}-\alpha^{2} b^{2}\right)^{2}}\left[t-\frac{b\left(9 k^{E}-\alpha^{2} b^{2}\right)}{9 k^{E}+\alpha^{2} b^{2}}\right]$ which is strictly negative if and only if $t<\min \left\{\frac{b\left(9 k^{E}-\alpha^{2} b^{2}\right)}{9 k^{E}+\alpha^{2} b^{2}}, \frac{b}{2}\right\}$. The claim then follows from applying argument similar to the ones used for the FDI case.

(ii) Consider the following set of parameterizations: $b=4, k^{F}=1$, and $\alpha=1$. For $c^{1}=\frac{4}{5}$ and $c^{2}=\frac{11}{10}$, we find that $z^{1}=\frac{96}{161}, z^{2}=\frac{99}{104}, c_{S}^{1}=c^{1}\left(1-\alpha z^{1}\right)=\frac{52}{161}$ and $c_{S}^{2}=c^{2}\left(1-\alpha z^{2}\right)=\frac{11}{208}$. Observe that $c^{1}<c^{2}$ and yet $c_{S}^{1}>c_{S}^{2}$.

Proof of Proposition 4: Noting (11), we obtain $\pi_{N}^{F}-\pi_{N}^{E} \geq 0 \Leftrightarrow \phi(\alpha, t) \leq 0$ where $\phi(\alpha, t) \equiv 2 \alpha^{2} c^{2}\left[9\left(k^{E}-k^{F}\right)(b-2 c)-t\left(9 k^{F}-4 \alpha^{2} c^{2}\right)\right]-2 t\left(9 k^{F}-4 \alpha^{2} c^{2}\right)\left(9 k^{E}-4 \alpha^{2} c^{2}\right)$.

We have

(a) $\phi(0, t)=-162 k^{E} k^{F}<0$, and $\phi(1, t)>0$ for all $t<\frac{9 c^{2}\left(k^{E}-k^{F}\right)(b-2 c)}{\left(9 k^{F}-4 c^{2}\right)\left(9 k^{E}-3 c^{2}\right)} \equiv \bar{t}$,

(b) $\phi_{t}(\alpha, t)=-\left[2 \alpha^{2} c^{2}\left(9 k^{F}-4 \alpha^{2} c^{2}\right)-2\left(9 k^{F}-4 \alpha^{2} c^{2}\right)\left(9 k^{E}-4 \alpha^{2} c^{2}\right)\right]<0$,

(c) $\phi_{\alpha}(\alpha, t)=4 \alpha c^{2}\left[9\left(k^{E}-k^{F}\right)(b-2 c)+4 t\left(9 k^{E}-4 \alpha^{2} c^{2}\right)+2 t\left(9 k^{F}-4 \alpha^{2} c^{2}\right)+4 \alpha^{2} c^{2}\right]>0$. It follows form (a) and (c) that there exists $\alpha(t) \in(0,1]$ such that $\alpha \leq \alpha(t) \Rightarrow$ $\pi_{N}^{F}-\pi_{N}^{E} \geq 0$ for $t<\bar{t}$. Also, for all $t<\bar{t}, \alpha^{\prime}(t)=-\frac{\phi_{t}(\alpha, t)}{\phi_{\alpha}(\alpha, t)}>0$ which implies $\alpha(t)$ is strictly increasing in $t$. For $t>\bar{t}, \alpha(t)=1$ and consequently $\alpha^{\prime}(t)=0$. 
Proof of Proposition 5: In the main text, we showed that $\alpha^{*}(t)=1$ for $t \geq \bar{t}$. We also proved that there exists $t_{1}>0$ such that $\alpha^{*}(t)=1$ for $t \leq t_{1}$. Here, first we prove that there exists $t_{2}<\bar{t}$ such that $\alpha^{*}(t)=\alpha(t)<1$ for all $t \in\left(t_{2}, \bar{t}\right)$. Suppose $t_{1}<t<\bar{t}$ and let $t \rightarrow \bar{t}$. From Proposition 4 we already know that for all such $t$ firm $N$ chooses FDI if $\alpha \leq \alpha(t)$ and $\alpha(t)<1$. It suffices to show that $\lim _{t \rightarrow \bar{t}}\left[W^{F}(\alpha(t))-W^{E}(1)\right]>0$. Denote $z^{F}$ and $z^{E}$ in equations (8) and $(9)$ as $z^{F}(\alpha)$ and $z^{E}(\alpha)$ respectively. For any given $\alpha \in[0,1]$,

$$
\begin{aligned}
& W^{F}(\alpha)=\frac{\left[2 b-c\left(1-\alpha z^{F}(\alpha)\right)\right]^{2}}{18}+\frac{\left[b-2 c\left(1-\alpha z^{F}(\alpha)\right)\right]^{2}}{9}-k^{F}\left(z^{F}(\alpha)\right)^{2}, \\
& W^{E}(\alpha)=\frac{\left[2 b-c\left(1-\alpha z^{E}(\alpha)\right)-t\right]^{2}}{18}+\frac{\left[b-2 c\left(1-\alpha z^{E}(\alpha)\right)+t\right]^{2}}{9}-k^{E}\left(z^{E}(\alpha)\right)^{2} .
\end{aligned}
$$

Continuity of $\alpha(t)$ in $t$ implies that $\lim _{t \rightarrow \bar{t}} \alpha(t)=\alpha(\bar{t})=1$. This finding, together with continuity of $W(\alpha)$ in $\alpha$, implies that

$$
\lim _{t \rightarrow \bar{t}} W^{F}(\alpha(t))-W^{E}(1)=\left[W^{F}(1)-W^{E}(1)\right]_{t \rightarrow \bar{t}} .
$$

It follows from (11) that $\alpha c\left(z^{F}-z^{E}\right)-2 t=0$ if firm $N$ is indifferent between exports and FDI. Using this, we obtain

$$
\left[W^{F}(1)-W^{E}(1)\right]_{t \rightarrow \bar{t}}=\frac{\bar{t}\left[24 b-30 c+15 c z^{F}(1)+15 c z^{E}(1)+3 \bar{t}\right]}{18}-\left(k^{F}\left(z^{F}(1)\right)^{2}-k^{E}\left(z^{E}(1)\right)^{2}\right) .
$$

Equating marginal cost with the marginal benefit of investment in $z$ gives $k^{g} z^{g}=\frac{2 \alpha c}{3} q_{S}^{g}$ ( $g \in\{E, F\})$ Using this, we have the following with $\alpha=1$ :

$$
\begin{aligned}
k^{F}\left(z^{F}(1)\right)^{2}-k^{E}\left(z^{E}(1)\right)^{2} & =\frac{2 c}{3}\left[\left(q_{S}^{F}-q_{S}^{E}\right) z^{F}(1)+q_{S}^{E}\left(z^{F}(1)-z^{E}(1)\right)\right] \\
& =\frac{\bar{t}\left[12 c z^{F}(1)+8 b-16 c+16 c z^{E}(1)+8 \bar{t}\right]}{18} .
\end{aligned}
$$

The last equality follows from $q_{S}^{F}-q_{S}^{E}=\bar{t}$ where the equality holds because $c\left(z^{F}-\right.$ $\left.z^{E}\right)-2 t=0$ with $\alpha=1$. Then we obtain

$$
\left[W^{F}(1)-W^{E}(1)\right]_{t \rightarrow \bar{t}}=\frac{\bar{t}\left[16 b-14 c+2 c z^{E}(1)+\bar{t}\right]}{18}>0
$$

That $\alpha^{* \prime}(t)>0$ for all $t \in\left(t_{2}, \bar{t}\right)$ follows from noting that (a) $\alpha^{* \prime}(t)=\alpha^{\prime}(t)$ for these values of $t$ and (b) $\alpha^{\prime}(t)>0$ (by Proposition 4). 


\section{REFERENCES}

Aitken, B. J., Harrison, A. E., 1999. Do domestic firms benefit from direct foreign investment? evidence from Venezuela. American Economic Review 89, 605-18.

Barry, F., Gorg, H., Strobl, E., 2005. Foreign direct investment and wages in domestic firms in Ireland: productivity spillovers versus labor market crowding out. International Journal of Business and Economics 12, 67-84.

Bilir, K., 2014. Patent laws, product life cycle lengths, and multinational activity. American Economic Review 104, 1979-2013.

Branstetter, L. G., 2001. Are knowledge spillovers international or intranational in scope? Microeconometric evidence from the U.S. and Japan. Journal of International Economics 53, 53-79.

Branstetter, L., Fisman, R., Foley, C. F., 2006. Do stronger Intellectual property rights increase international technology transfer? Empirical evidence from U.S. firmlevel panel data. Quarterly Journal of Economics 121, 321-349.

Branstetter, L., Saggi, K., 2011. Intellectual property rights, Foreign Direct Investment, and industrial development. Economic Journal 121, 1161-91.

Branstetter, L., Fisman, R., Foley, C. F., Saggi, K., 2011. Does intellectual property rights reform spur industrial development? Journal of International Economics 83, 27-36.

Chakraborty, C., Nunnenkamp, P., 2008. Economic reforms, FDI, economic growth in India: a sector level analysis. World Development 36, 1192-212.

Chin, J. C., Grossman, G. M., 1989. Intellectual Property Rights and North-South Trade in R. Jones and A. Krueger (eds.), The Political Economy of International Trade Policy, Basil Blackwell.

Deardorff, A., 1992. Welfare effects of global patent protection. Economica 59, 35-51.

Diwan, I., Rodrik, D., 1991. Patents, appropriate technology, and North-South trade. Journal of International Economics 30, 27-47.

Dimelis, S., Louri, H., 2002. Foreign ownership and production efficiency: a quantile regression analysis. Oxford Economic Papers 54: 449-69.

Djankov, S., Hoekman, B., 2000. Foreign investment and productivity growth in Czech enterprises. World Bank Economic Review 14, 49-64.

Eaton, J., Kortum, S., 1999. International patenting and technology diffusion: theory and measurement. International Economic Review 40, 537-70.

Ekholm, K., Forslid, R., Markusen, J. R., 2007. Export-platform foreign direct investment. Journal of the European Economic Association 5, 776-795. 
Ethier, W., Markusen, J. R., 1996. Multinationals, Technical Diffusion, and Trade. Journal of International Economics 41, 1-28.

Glass, A. J., Saggi, K., 2002. Intellectual Property Rights and Foreign Direct Investment. Journal of International Economics 56, 387-410.

Grossman, G., Helpman, E., 1991. Endogenous Product Cycles. Economic Journal $101,1214-29$.

Grossman, G., Lai, E., 2004. International protection of intellectual property. American Economic Review 94, 1635-53.

Griffith, R., Redding, S., Van Reenen, J., 2003, R\&D and absorptive capacity: Theory and empirical evidence. Scandinavian Journal of Economics 105, 99-118.

Grünfeld, L. A., 2006, Multinational production, absorptive capacity, and endogenous R\&D spillovers. Review of International Economics 14, 922-40.

Helpman, E., 1993. Innovation, imitation, and intellectual property rights. Econometrica $61,1247-80$.

Holstmann, I., Markusen, J. R., 1987, Licensing versus direct investment: a model of internalization by multinational enterprise. Canadian Journal of Economics 20, 464481.

Horiuchi, E. and Ishikawa, J., 2009, Tariffs and Technology Transfer through an Intermediate Product. Review of International Economics 17, 310-326.

Ishikawa, J., 2007, Trade Liberalization and Technology Transfer through an Intermediate Product. International Economy 11, 3-10.

Ishikawa, J. and Horiuchi, E., 2012, Strategic Foreign Direct Investment in Vertically Related Markets. Economic Record 88, 229-242.

Javorcik, B., 2004. Does foreign direct investment increase the productivity of the domestic firms? in search of spillovers through backward linkages. American Economic Review 94, 605-27.

Kabiraj, T., Marjit, S., 1993. International technology transfer under potential threat of entry : A Cournot-Nash framework. Journal of Development Economics 42, 75-88.

Kabiraj, T., Marjit, S., 2003. Protecting consumers through protection: The role of tariff-induced technology transfer. European Economic Review 47, 113-24.

Kanwar, S., 2012. Intellectual property protection and technology licensing: The case of developing countries. Journal of Law and Economics 55, 539-564.

Kathuria, V., 2000. Productivity spillovers from technology transfer to Indian manufacturing firms. Journal of International Development. 12, 343-69. 
Keller, W., 2002. Geographic localization of international technology diffusion. American Economic Review 92, 120-42.

Keller, W., 2004. International technology diffusion. Journal of Economic Literature $42,752-82$.

Lai, E. L.-C., 1998, International intellectual property rights protection and the rate of product innovation. Journal of Development Economics 55, 133-53.

Maskus, K. E., 2000. Intellectual property rights in the global economy, Washington, DC: Institute for International Economics.

Maskus, K. E. and McDaniel, C., 1999. Impacts of the Japanese patent system on productivity growth, Japan and the World Economy 11, 557-4.

Motta, M., Norman G., 1996, Does economic integration cause foreign direct investment? International Economic Review 37, 757-783.

Mukherjee, A., Pennings, E., 2006. Tariffs, licensing and market structure, European Economic Review 50, 1699-1707.

Naghavi, A., 2007, Strategic intellectual property rights policy and North-South technology transfer. Review of World Economics 143, 55-78.

Saggi, K., 1996, Entry into a foreign market: Foreign direct investment vs licensing. Review of International Economics 4, 99-104.

Saggi, K., 2002, Trade, Foreign Direct Investment, and International Technology Transfer: A Survey. World Bank Research Observer 17, 191-235.

Sawada, N., 2010, Technology gap matters on spillover. Review of Development Economics 14, 103-120.

Suyanto, Salim, R., Bloch, H., 2009. Does Foreign Direct Investment Lead to Productivity Spillovers? Firm Level Evidence from Indonesia World Development 37, 1861-76.

Taylor, M. S., 1993, TRIPS, trade and technology transfer. Canadian Journal of Economics 26, 625-637.

Tintelnot, F., 2017, Global Production with Export Platforms. Quarterly Journal of Economics 132, 157-209.

Yang, G., Maskus, K. E., 2009. Intellectual property rights, technology transfer and exports in developing countries. Journal of Development Economics 90, 231-36.

Žigić, K., 1998. Intellectual property rights violations and spillovers in North-South trade. European Economic Review 42, 1779-99.

Žigić, K., 2000. Strategic trade policy, intellectual property rights, and North-South trade. Journal of Development Economics 61, 27-60. 